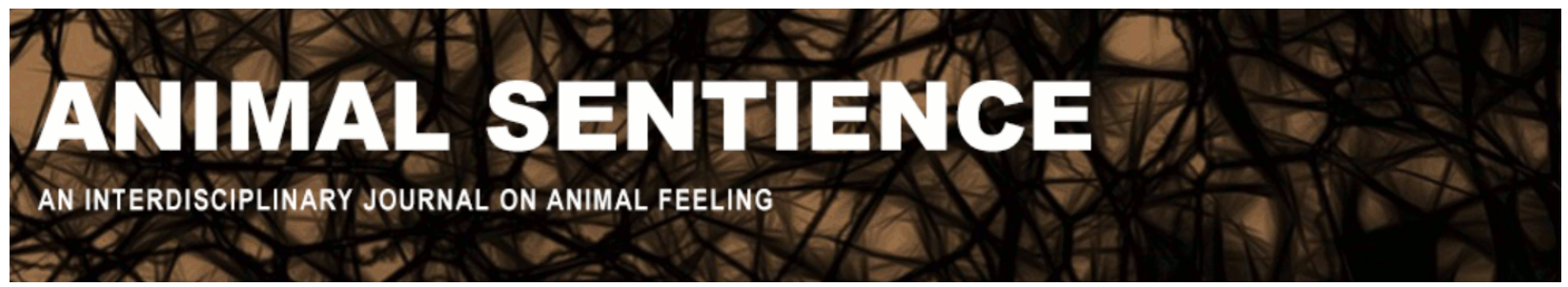

Donaldson, Sue and Kymlicka, Will (2016) Linking animal ethics and animal welfare science. Animal Sentience 5(5)

DOI: $10.51291 / 2377-7478.1006$

Date of submission: 2015-03-20

Date of acceptance: 2015-12-13

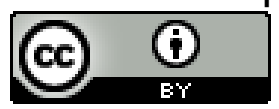

This article has appeared in the journal Animal

Sentience, a peer-reviewed journal on animal

cognition and feeling. It has been made open access,

free for all, by WellBeing International and deposited

in the WBI Studies Repository. For more information,

please contact

wbisr-info@wellbeingintl.org.

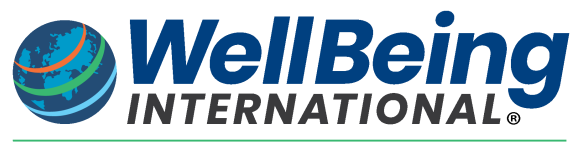

SOLUTIONS FOR PEOPLE, ANIMALS AND ENVIRONMENT 


\title{
Linking animal ethics and animal welfare science
}

\author{
Commentary on Broom on Animal Welfare
}

\author{
Sue Donaldson \& Will Kymlicka \\ Department of Philosophy \\ Queens University
}

\begin{abstract}
Broom (2014) argues that theories of animal ethics need to be better informed by the findings of animal welfare science. We agree, but argue that animal welfare science in turn may need to ask different questions. To date it has largely assumed that society will continue to treat domesticated animals as a caste group that exists to serve us, and that animal welfare is to be improved within that legal and political framework. We offer an alternative model of humananimal relations, and discuss what kind of animal welfare science it would require.
\end{abstract}

Sue Donaldson cliffehanger@sympatico.ca is an independent researcher and writer. She is co-author, with Will Kymlicka, of Zoopolis: A Political Theory of Animal Rights (Oxford University Press, 2011). Their most recent work is "Farmed Animal Sanctuaries: The Heart of the Movement? A socio-political perspective." Sue is also a co-founder of Queen's Animal Defence, an advocacy

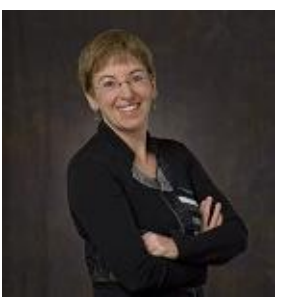
group working for interspecies social justice.

http://queensanimaldefence.org

Will Kymlicka kymlicka@queensu.ca is Canada Research Chair in Political Philosophy at Queen's University in Kingston, Canada. His current research focuses on "The Frontiers of Citizenship," and in particular on struggles to extend norms and practices of citizenship to historically excluded groups, ranging from children and people with intellectual disabilities to indigenous peoples and animals.

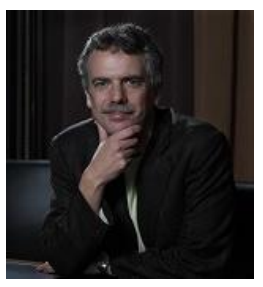
http://post.queensu.ca/ kymlicka/

As the title indicates, Broom's (2014) book straddles two major topics. First, it explains current scientific understandings of the concept of sentience, and reviews evidence for the existence of sentience in various kinds of animals. Second, the book explains the concept of animal welfare and describes a range of methodologies for assessing welfare, along with some of the knowledge that has emerged from these investigations. Understanding the complexities of sentience helps shed light on which animals, in which situations, and in which ways, have forms of welfare to which humans should attend.

Our own work is on animal ethics, so we are particularly interested in how animal welfare science (hereafter AWS) can inform the development of moral and political theories of animal 
rights. Broom, like Dawkins (2012), Fraser (2008), and other animal welfare scientists, states that theories of animal ethics need to be better informed by scientific findings regarding sentience and animal welfare. We agree with that observation, but we would argue that if AWS is to inform animal ethics, it may need to set different questions for itself.

As Broom notes, AWS emerged in response to concerns about the welfare of animals in industrialized agriculture - those raised as Animal Machines, in Ruth Harrison's (1964) parlance. AWS has confirmed the egregious welfare conditions of many farmed animals, and has helped to inform reforms. In that sense, AWS provides a critical lens on existing practices. But in another sense, AWS typically operates with the assumption that industrialized agriculture will continue, and hence that animals will continue to be treated as a caste group that exists to serve human interests. Animals will continue to be bred, raised, and killed for our benefit, a reality enabled and enforced through their status as property. AWS, in that sense, is about creating a more humane caste system. This is implicit in Broom's own discussion, as there are repeated references to improving welfare within "animal usage systems" (125) or "animal production systems" (128). This is not surprising, since AWS is largely funded by corporate interests or by government departments that have a mandate to defend and promote the agricultural sector.

For many animal rights theorists, this assumption that animals should be treated as property and as a caste group is fundamentally unacceptable from a moral point of view. We cannot treat other sentient beings as instruments to serve our interests.

This tenet of animal rights theory rests on empirical premises about which beings possess sentience, and as Broom's review of scientific knowledge shows, this is a complicated question. His discussion suggests there is no single bright line concerning sentience, but rather a matrix of features (awareness, feelings, and cognition) that occur in different forms, degrees, and combinations in different animals who have developed along different evolutionary paths. This is a salutary reminder of the need for humility and caution when ethicists make pronouncements about sentience. However, as Broom is the first to emphasize, these complexities provide no basis for disputing the sentience of the domesticated animals who are at the heart of our "animal production systems." Whatever complexities arise in thinking about sentience in molluscs and insects, they provide no basis for disputing the sentience of pigs, cows, sheep and chickens, whose awareness, feelings, and cognition have all been amply documented. And from an animal rights point of view, this evidence is sufficient to condemn the caste model underlying "animal production systems" as morally unacceptable.

And so the challenge is to develop alternative models of relations between humans and domesticated animals. If it is not appropriate to see animals as a caste group that exists to serve humans, then we need to start from different assumptions, and ask different questions. In our own work, we start from the assumption that domesticated animals are members of our society, and as such have membership rights. We have brought them into our society through domestication, and incorporated them into our schemes of social cooperation and economic production; justice requires recognition of their right to membership. We also suggest that the 
legal tool we use to replace relations of caste hierarchy with relations of equal membership is citizenship. Domesticated animals should therefore be seen as co-citizens in a shared society, and the norms which govern our shared life must therefore be as responsive to their subjective good as to ours (Donaldson and Kymlicka 2011).

Clearly, any attempt to move in this direction will require extensive knowledge of the preferences, dispositions and capacities of domesticated animals. It is not enough to know that domesticated animals are sentient; we also need more fine-grained information about their subjective good. AWS is potentially of vital importance in fleshing out our version of animal rights (or indeed of any version of animal ethics that seeks to move beyond the caste model).

But if AWS is to inform new models of human-animal relations, it will need to ask different questions. Most fundamentally: what sort of relations do domesticated animals want to have with us? That is the central question that members of a society need to ask of each other. One of the most striking features of AWS is that it has never explicitly addressed this question, at least not in these terms. Of course, this is not a single or simple question, and to make progress on it, we need to disaggregate it into more specific questions, including questions about capacities for inter-species sociability (which domesticated animals can enjoy what types of socializing with which humans), capacities for inter-species cooperation (which kinds of shared activities, including cooperative work, are possible and meaningful for which domesticated animals), and preferences and choices (given options, what kinds of family relationships, social relationships, work relationships, and play activities would domesticated animals choose?).

In our view, AWS has not yet tackled these questions in the systematic way that would enable us to inform a membership-based, anti-caste theory of animal ethics. There are, however, intriguing pieces of evidence in Broom's book that provide some helpful starting points. Broom reviews a great deal of evidence that challenges common prejudices about the capacities of domesticated animals. They are not stunted, inferior, and less capable versions of wild animals, nor are they genetically predestined to a future of fixed dependency on humans. A variety of different lives are possible in the future. In some cases, these lives might involve a gradual or partial exit from human society, since many domesticated animals are capable of taking care of themselves, and they may gravitate towards a kind of rewilding. But in other cases, these possible lives might involve more extensive interaction with humans. Broom rightly challenges the idea that what is best for domesticated animals is what is natural or authentic in terms of how their wild animal counterparts live. A key change that distinguishes domesticated animals from their ancestors is that they tolerate, and often desire, contact with humans. This means that, unlike many wild animals, they have an opportunity to be part of a society with humans that can offer them many opportunities and advantages: a chance to escape often relentless demands for survival and instead explore opportunities for a diversity of experiences, novel ways of playing and learning, and the stimulations of multi-species society and friendships.

So both greater exit from human society and greater inclusion within it are options for some domesticated animals, depending on their circumstances, and an anti-caste membership model would commit itself to enabling domesticated animals to explore these options. 
This raises the question of how we interpret the preferences and choices of animals. As Broom shows, AWS offers a variety of methodologies for understanding animals' feelings, desires, and motivations. In the human case, we often rely on self-report for information about these inner states, but as Broom notes, self-report is often false or misleading. And so the fact that animals can't tell us about their inner states isn't necessarily the impediment we think it is. A variety of strategies exist for peeking inside the black box, bringing evidence from different domains (behavior, interpretation of physiognomy, physiological measures, etc.), and devising thoughtful (and ethical) experimental situations for assessing motivations and response. One of the ingenious studies Broom mentions revealed that cows, given a problem-solving task, experience the satisfaction of a "eureka" moment when they solve a problem. Cows derive pleasure from learning. This is good to know, and immediately enriches our sense of the world of possibilities. But we can only fully envisage those possibilities once we think outside the constraints of a caste model of human-animal relations.

In short, AWS offers valuable methodologies, and some intriguing evidence, that can be useful to anyone concerned with how we can live in just and flourishing relationships with other animals. However, if AWS is to fulfill its potential of informing animal ethics, it needs to sever the umbilical cord with "animal production systems."

\section{References}

Broom, D.M. (2014). Sentience and animal welfare. Wallingford: CABI.

Dawkins, M. (2012). Why animals matter: animal consciousness, animal welfare and human well-being (Oxford: Oxford University Press).

Donaldson, S. and Kymlicka, W. (2011). Zoopolis: A Political Theory of Animal Rights (Oxford: Oxford University Press).

Fraser, D. (2008). Understanding animal welfare: the science in its cultural context (Oxford: Wiley-Blackwell).

Harrison, R. (1964). Animal machines: the new factory farming industry (London: Vincent Stuart). 